\title{
The Design and Implementation of Scientific Research Management System in University
}

\author{
Da Yang ${ }^{1, a^{*}}$ \\ ${ }^{1}$ School of Jilin Agricultural University, Jilin, China \\ ayangnan1983116@163.com
}

Keywords: University; Information; Scientific research; Management system

\begin{abstract}
There are amount of work about scientific research management and many disadvantages of scientific research management which rely on manual management. People use information technology to construct a system. The system can effectively solve the problem and realize the standardization of scientific research management in university.
\end{abstract}

\section{Introduction}

With the continuous development of science research education, scientific research education becomes a kind of core work in university. The construction of scientific research management system in university has become an essential way to strengthen management level of scientific research. Scientific research management mainly revolves around result and project management and it is a kind of data-centric management mode. At present, people conduct a simple research after input the data by themselves. This kind of management way is relatively backward. This kind of way not only increase the intensity of management work but also led to the division of research data is not comprehensive, it can't accurately response the scientific research of school as a whole. The construction of scientific research management system can form a dynamic data center of scientific research and management platform, the system can collect, process, storage and react the relevant data of scientific research level in school. The system also can provide support for scientific decision by the real-time accurate information.

\section{The Design of Scientific Research Management System}

The system of scientific research management includes organization management, project management, personnel management, result management, scientific research statistics and system maintenance. Its structure as shown in Fig. 1.

\section{The Module of Organization Management}

This module collects the basic information of college, research institute and key laboratory to make basic data enter into the system of scientific research management. The data of this module enter into the system mainly come from affiliate.

\section{The Module of Project Management}

The module of project management mainly collects the project information of scientific research which includes all kinds of horizontal and vertical projects. The leader of related project need to input some details of project, such as project name, project time, sources of funds and personnel etc. The users or administrators of the highest management level about the project report and audit in the module can add, delete and modify the transverse project etc. The module can manage longitudinal research project. Implement the function of "approving and initiating a project" that should place the project application report into a temporary project data in the table, then deposited in the permanent table after the Scientific Research Office approve. 


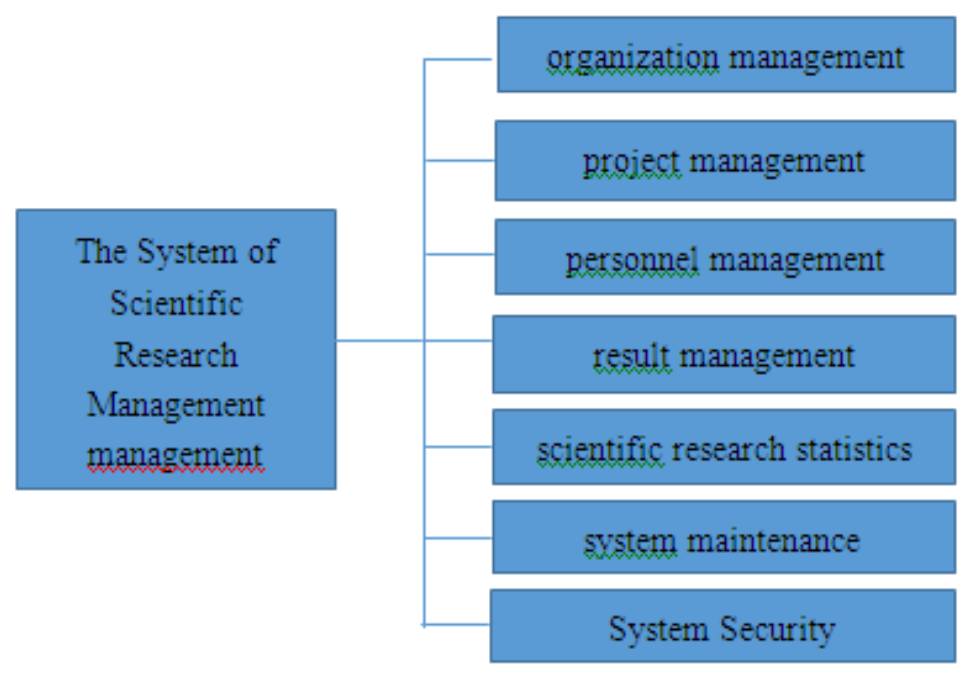

Figure 1. design composition structure of system

\section{The Module of Personnel Management}

The module of personnel management mainly collects the nature and academic situation of science research units. Natural conditions mainly include name, sex, birth, educational background and school etc. Organization is provided by the agency management module automatically. Academic situation mainly includes research direction, professor course and research subject etc. This module mainly takes the registration and management on the information of expert in colleges and universities, such as scientific research and academic exchange. The personnel of scientific research management can inquire the expert's information such as name and unit. The rapid and accurate queries play a supporting role for scientific research management decisions. In addition, people fill many forms when they apply the project and there are many duplicates, such as gender, age, title and the previous research result etc. After inputting the database of expert, these basic information can be called up what can avoid the repeated labor researchers and they can increase their information and authorization. This kind of way can reduce personnel workload of scientific research management. The establishment of database reflects the concept of people-oriented management. Experts can find their information on any computer through the network and they can upload and display pictures. People can find the database of experts according to the disciplines information in order to choose the evaluation experts (Fig. 2).

\section{The Module of Result Management}

This module mainly collects academic papers of scientific research personnel. This module is consists of periodical management module which collect names, organization competent, level, ISSN information of the different journals at home and abroad to complete the academic achievements of automatic identification. Result management is an extremely important part of scientific research management in university. Result communication is the ladder of the progress of scientific research in colleges and universities. The protection of intellectual property is an effective guarantee for popularization and application of scientific research achievements. The two parts of management work are not allowed to ignore. Because result communication is a mean to improve their academic accomplishment. In order to improve learning effects, it is necessary to record and store the academic exchange activities. And the personnel of scientific should arrange academic exchange activities to promote the communication activities. The information system of scientific research management developed in order to realize, modify and delete scientific research/patent and so on. 


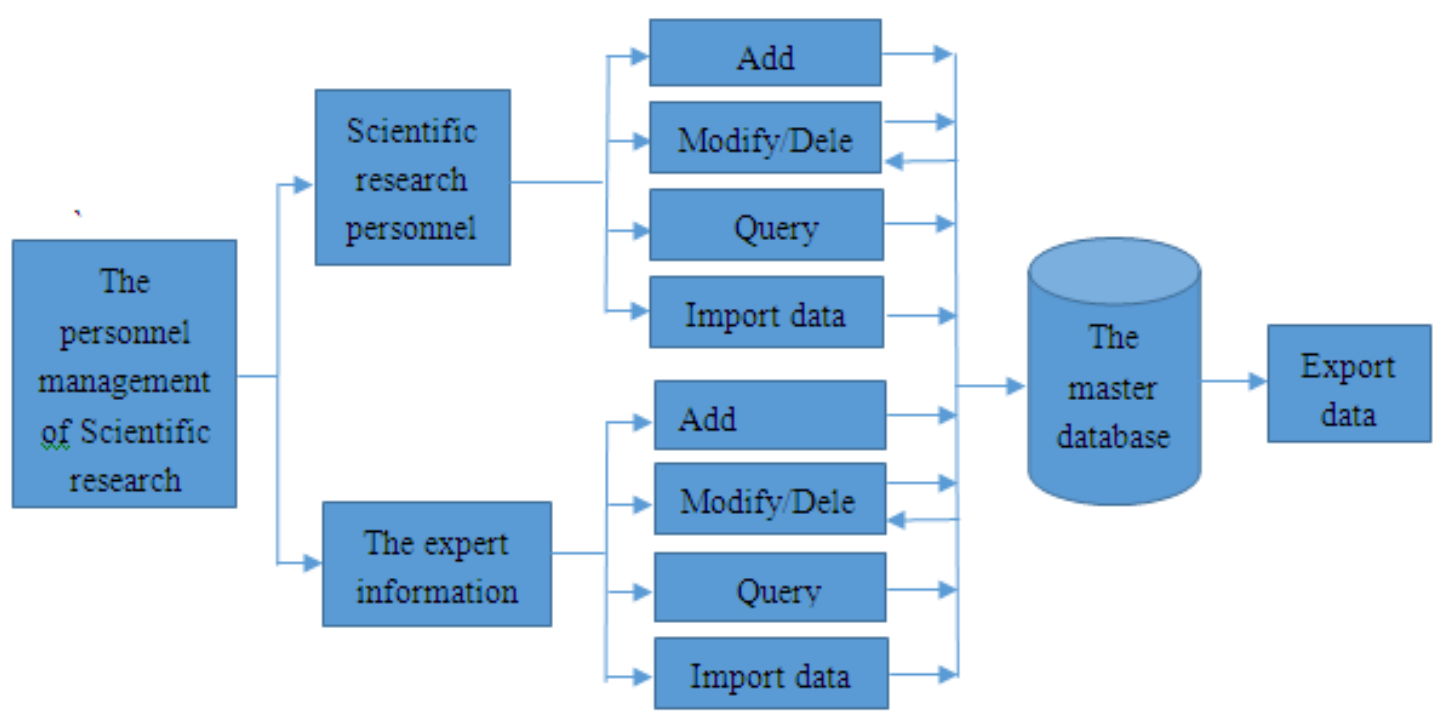

Figure 2. The Module of Personnel Management

\section{The Module of Scientific Research Statistics}

This module can realize personnel information statistics, scientific research statistics, project information statistics. In order to realize diversified statistics and achieve a variety of retrieval methods, all statistical work can be done by setting different statistical condition combination and meet the demand of the complex statistics. At the same time, in order to make the statistical result have visualization. The system can be in a variety of graphical display results such as the commonly used chart.

\section{The Module of System Maintenance}

The module mainly takes charge the management and permission assignment for users of scientific research management system. Assign the appropriate system permissions according to the user's affiliated institutions and work content to prevent illegal user and unauthorized user of the backstage. Scientific research data from tampering, deletion and error operation to ensure the security of the backstage data. At the same time, the module is also responsible for the backstage database initialization; eliminate redundant data, backup daily database and disaster recovery etc.

\section{The Module of System Security}

In order to ensure that only authorized users can access resources, in the mode of the $\mathrm{B} / \mathrm{S}$, the whole process of access requires the user to identify, in order to prevent the illegal user intrusion and legitimate users of the wrong operation so that the database system was destroyed. So for the user and administrator set up two entrances, for different users to provide a different login interface. After the user login, you can modify the basic personal information and password; submit personal information and research results, query personal information and scientific research score, online reporting project etc. The leaders can only query, statistics and analysis of the information to assist decision making. The department leaders can manage the personal information and project of the scientific research personnel of the department, allows adding and modifying the basic information of new users in the department, to review the relevant information of scientific research personnel and use related function modules. The research department manager to review and modify the department staff to submit information, project information, information results and the use of all functional modules to manage the whole school of scientific research information. System 
administrator for the operation of the entire system management, for all levels of managers and leaders assigned account and password, but they do not have the right to audit and modify the project management.

\section{The Implementation of the System}

The main technical framework of the system is based on the mode of $\mathrm{B} / \mathrm{S}$ and the technology of net. The client software of $\mathrm{B} / \mathrm{S}$ structure uses standard browser, without the use of special client software, the direct interaction between client and web server, web server and application server interaction, application server to complete most work of the application system. The web server and application server of the system are put together. There are two popular modes of management information system at present: B/S mode and C/S mode. Among them, $\mathrm{B}$ is the browser and $\mathrm{C}$ is the client, the two models have different characteristics and advantages.

$\mathrm{C} / \mathrm{S}$ mode mainly takes charge the customer application, server management, program, middleware components. The client application is the components of system users interact with the data. The server is responsible for the management of system resources effectively. The middleware is in charge of connecting customer application and server management procedures, to meet query data management requirements. The $\mathrm{C} / \mathrm{S}$ model has the advantages of strong interactivity, high data security, small network traffic and fast speed of completion.

The mode of $\mathrm{B} / \mathrm{S}$ is a kind of new model of MIS system platform which is based on Web technology. Browser sends the requests such as change, delete, increase and decrease of local user to Web server through the HTTP protocol. Then the system finishes work by that the Web server connecting the database server. That is to say the server part of the traditional $\mathrm{C} / \mathrm{S}$ model is decomposed into browser application server and database server three-layer structure of server system. Compared with $\mathrm{C} / \mathrm{S}$ mode, the client of $\mathrm{B} / \mathrm{S}$ mode just needs a browser that a variety of tasks can be completed. Using B/S mode can make the management of science and technology personnel or departments of scientific research workers have a higher openness and flexibility, efficiency is greatly increased.

\section{Summary}

The design and implementation of this system can give conveniences to the collection, process and storage of scientific research data, make scientific research data are more accurately in an all-round way and improve the efficiency and level of scientific research management work. But at the same time, the system has some deficiencies. For example, system interface design is relatively simple. In the future, the system will be improved to solve these problems and make the system perfect gradually.

\section{References}

[1] Nagaratnam N, Nadalin A,Janson P,et al. Security Architec-ture for Open Grid Services[Z].OGSA Security Workgroup,2003.

[2] Welch V, Siebenlist F, Foster I,et al. Security for Grid services[A].In: Proc 12th IEEE International Symposium on High Performance Distributed Computing[C].Seattle, WA,USA:IEEE Computer Society, 2003.48- 57.

[3] Nagaratnam N, Nadalin A, Janson P, et al. Security Architec-ture for Open Grid Services [Z].OGSA Security Workgroup, 2003.

[4] Foster I, Kesselman C, Tuecke S. The Anatomy of the Grid: Enabling Scalable Virtual Organizations [J].International Jour-nal of High Performance Computing Applications, 2001, 15(3): 200- 222. 